\title{
Optimization of fatigue strength of selective inhibition sintered polyamide 12 parts using RSM
}

\author{
Mesfin Sisay ${ }^{*}$ and Esakki Balasubramanian \\ Department of Mechanical Engineering, Vel Tech Rangarajan Dr. Sagunthala R\&D Institute of Science and Technology, \\ Chennai 600062, India
}

Received: 3 April 2020 / Accepted: 2 June 2020

\begin{abstract}
Selective inhibition sintering (SIS) is a powder based that fabricate functional parts through fusion of powder bed on a layer by layer basis. Being a new fabrication method, the correlation between process variables and part properties are not fully comprehended. Polyamide 12 (nylon 12) is one of the widely used materials in powder based AM processes including SIS. Therefore, in this work, the effect of critical SIS process parameters on the fatigue behavior of polyamide 12 parts was experimentally investigated, and the parameter settings were optimized to maximize fatigue strength. The number of experimental runs was determined based on BoxBehnken design, and specimens were fabricated as per ASTM D7791. Specimens were tested by subjected them to fluctuating loading at a frequency of $3 \mathrm{~Hz}$. The test results were analyzed using Minitab statistical analysis software. From the ANOVA result, it was identified that the fatigue life of SIS parts is significantly influenced by layer thickness, heater temperature, and heater feed rate. Optimization of process variables settings was performed using the Minitab response optimizer and maximum fatigue strength of 17.43 MPa was obtained. The verification experiment resulted in 17.93 MPa fatigue strength which is comparable to the predicted value and with the result from the literatures.
\end{abstract}

Keywords: Selective inhibition sintering / ANOVA / fatigue strength / inhibition / RSM

\section{Introduction}

Additive manufacturing (AM) processes are superior over the conventional fabrication methods in that they are not limited by geometric complexity of the part, their fabrication time and cost is relatively shorter and cheaper for low production volume [1]. Because AM does not require any tooling while fabricating parts with intricate details and comparing with conventional fabrication techniques it reduces the product lead time by about $60 \%$ [2]. Based on the state of the starting materials, AM is classified into three categories such as solid-based, liquidbased and powder-based. Selective laser sintering (SLS) is the most widely used powder-based AM process for its applicability to processing a wide range of engineering materials including polymers without requiring support structure [3]. SLS uses a $\mathrm{CO}_{2}$ laser as a heat source for sintering the powder layer and build a three-dimensional solid $[4,5]$. The high power laser heating element incurs cost for SLS to build part which can be significantly reduced through replacing it with a low cost heating element [6].

\footnotetext{
* e-mail: mesfins245@gmail.com
}

Selective inhibition sintering (SIS) is a modified version of SLS where the high power carbon dioxide laser heating element is replaced with an infrared lump [7]. In the SIS process, a part is created by selective sintering of thin layers of powdered polymer in the part's body and inhibition at the part boundary. In this process, the selected area within the powder layer is wetted by printing an inhibitor liquid.

SIS offers some superior advantages over SLS. For instance, it can produce parts at a cheaper cost due to shorter printing time by sweep sintering and cheaper heating element [7]. Besides, SIS process fabricates parts from indigenously available polymer powder using indigenously prepared inhibitor solutions that play a part in reducing the cost of SIS fabricated parts.

Commercially available powder based SLS systems are very costly. The SIS system is cheaper because the high cost laser system is replaced with cost effective infrared heater system. In addition, indigenously available polymer powders can be customized for the SIS system and various polymers materials options can be possible in contrast to SLS system. Since the system is developed using an open architecture of controller and software platforms it can be very well utilized by researchers and industrialists to build 
prototypes. The significance of the present work is to develop a cost effective and adaptable system to the users who have to build functional prototypes at lower cost.

For any manufactured parts, functionality depends on the property of the starting material as well as the fabrication process parameters $[8,9]$. Mechanical property is one aspect of quality that determines the load carrying and transmitting behavior of fabricated parts. Khoshnevis et al. [10] studied process variables that affect the mechanical strength of SIS parts, and they have identified several SIS process parameters that influence the mechanical characteristics. Amongst these parameters layer thickness, heater temperature, heater feed rate, and printer feed rate were listed as the most critical factors that play a vital role in influencing the mechanical behavior of fabricated parts. However, since the SIS system is still in its nascent stage, the relationship between these predictor variables and material properties has not been fully comprehended yet.

Few studies have been done to comprehend the association of the aforementioned factors and the properties of the material to be processed in terms of affecting the mechanical characteristics of the SIS fabricated parts. Rajamani et al. [11] investigated tensile and flexural strength of parts fabricated from high-density polyethylene (HDPE) using the SIS process by response surface methodology (RSM) and desirability approach. They reported that the process can produce parts with an acceptable level of mechanical characteristics. Furthermore, Esakki et al. [12] applied an intelligent prediction system to predict the tensile strength and flexural strength of the HDPE part made using the SIS system. It was reported that the mechanical property of SIS fabricated parts is influenced by layer thickness, heater temperature, heater feed rate, and printer feed rate. Baligidad et al. [13] investigated the SIS process parameters' effect on the tensile property of an SIS made HDPE part. The result shows that tensile property is influenced by layer thickness, heater power, and heater feed rate. Moreover, Baligidad et al. [13] examined the effects of SIS process parameters: layer thickness, heater power, and heater feed rate on the storage modulus and lose modulus of polyamide 12 (PA 12) parts. The investigation results revealed that storage and loss modulus is maximized for low levels of layer thickness and heater power, and also high level of heater federate. All of these works were focused on the behavior of parts subjected to static loading conditions.

Though, most of the reported failure of mechanical components by the mechanical industries such as automobile and aerospace are associated with fatigue loading conditions even when parts are not directly subjected to cyclic loading [14-16]. Also, polyamide 12 is the most common engineering materials that are being processed by powder-based AM processes such as SIS system [13,17,18], SLS process [19-22] and multijet fusion (MJF) technology [23] due to its large processing window between crystallization and melting temperature [24,25]. Moreover, PA 12 has much application in automobile, aerospace and medical industries $[8,9]$.

However, only one published research work by Baligidad et al. [13] was found that investigated the SIS process variables' effect on the fatigue property of the final component. However, several researches have been carried out on the fatigue behavior of PA 12 parts fabricated through the SLS process. Fatigue properties of Nylon 12 parts fabricated using an SLS process have been studied by [26-28], and it was reported that an endurance limit of approximately $18 \mathrm{MPa}$ has been obtained. Munguia et al. [29] studied the response of an SLS manufactured nylon 12 parts to a pulsating load mode. From the results of the investigation, it was obvious that no significant variation in response was observed as a result of the mode of fatigue loading. However, even though PA 12 is a widely used thermoplastic material, no scientific work has been found focusing on SIS process parameters on fatigue behavior of PA 12 parts.

The aim of this study is, therefore, to examine the fatigue behavior of an SIS fabricated PA 12 parts under the influence of the process variable (layer thickness, heater temperature, heater, and printer feed rate) and to optimize parameters settings that resulted in the maximum number of cycles to failure. An experimental investigation was performed using Box-Behnken design and ANOVA using Minitab 18 statistical software was employed to study the main effect and interaction effect on the response variable. Finally, optimizations of SIS process variable settings that maximize fatigue property of PA12 parts have been done using the Minitab response optimizer function.

Furthermore, the approach followed for determining the fatigue life of the samples is using $\mathrm{S}-\mathrm{N}$ curves. To construct this curve many samples were required to be fabricated for each experimental run. For a single treatment combination, 15 samples were needed to plot the $\mathrm{S}-\mathrm{N}$ curve. Considering that polyamide 12 powder is expensive and the number of test samples required was many, the test needed significant investment in time and money.

\section{Experimental details}

\subsection{Material}

For this experimental study DuraForm ProX PA, which is a high strength material, was used. This material was supplied by 3D Systems Inc. (USA). According to the manufacturer, the average size of powder particles is $58 \mu \mathrm{m}$ [30]. The inhibitor solution was prepared by mixing a saturated aqueous solution of potassium Iodide (KI) and small Isopropyl alcohol. The mechanical, thermal, and physical properties of the selected powder are given in Table 1.

\subsection{Design of experiment}

Box-Behnken based response surface design was used to determine the number of experimental run and combinations of parameter levels that provide sufficient datasets that fits a second order response surface model. BoxBehnken method of experimental design needs only three levels of parameter settings where the third level is a midpoint value of the range of each parameter's settings. Based on the result of the preliminary investigation as well 
Table 1. Property of DuraForm ProX PA [31].

\begin{tabular}{ll}
\hline Powder property & Value \\
\hline Density (fabricated part) & $0.59 \mathrm{~g} / \mathrm{cm}^{3}$ \\
Mean powder particle size & $58 \mu \mathrm{m}$ \\
Particle size Range $90 \%$ & $25-92 \mu \mathrm{m}$ \\
Melting point: Tm & $184^{\circ} \mathrm{C}$ \\
Mechanical properties & $\mathrm{PA}$ \\
UTS & $44 \mathrm{MPa}$ \\
Tensile modulus & $1600 \mathrm{MPa}$ \\
Tensile elongation at break & $9 \%$ \\
Flexural modulus & $1285 \mathrm{MPa}$ \\
\hline
\end{tabular}

Table 2. Predictor variables and their setting ranges.

\begin{tabular}{lllll}
\hline S.N & Process parameters & Unit & Range & \\
\hline 1 & Layer thickness & $\mathrm{Mm}$ & 0.2 & 0.4 \\
2 & Heater temperature & ${ }^{\circ} \mathrm{C}$ & 220 & 240 \\
3 & Heater federate & $\mathrm{mm} / \mathrm{sec}$ & 3 & 3.5 \\
4 & Printer federate & $\mathrm{mm} / \mathrm{min}$ & 100 & 120 \\
\hline
\end{tabular}

as the report from the literature $[10,11,32]$ four parameters: layer thickness, heater temperature, heater feed rate and printer feed rate have been chosen as influencing process parameters of the mechanical characteristics of SIS fabricated parts.

Each process parameters and the range of their corresponding levels are shown in Table 2. The range of setting values were selected based on preliminary investigation carried out on DuraForm Prox PA (polyamide 12) powder.

The number of factors and number of experimental runs in Box-Behnken design of experiment is related using the following mathematical equation.

$$
N=2 K(K-1)+C_{p}
$$

where $N$ is the number of experimental runs; $K$ is the number of process parameters, and $C p$ is center point plus repetitions. Therefore, the experimental design for 4 factors with 3 levels has resulted in 24 runs. And 5 center point replicates were added in order to capture any nonlinear effect which makes the total experimental run 29 .

\subsection{Specimen fabrication}

The SIS system, shown in Figure 1, was developed at the laboratory of Center for Autonomous Systems Research, Vel Tech Rangarajan Dr.Sagunthala R\&D Institute of Science and Technology to fabricate the samples.

The system consists of various parts such as feed tank, build platform, inhibition depositor and infrared heater. The feed tank is used as a reservoir for holding the PA 12 powder, whereas the build platform is the part on which components are built. The build volume of the machine is

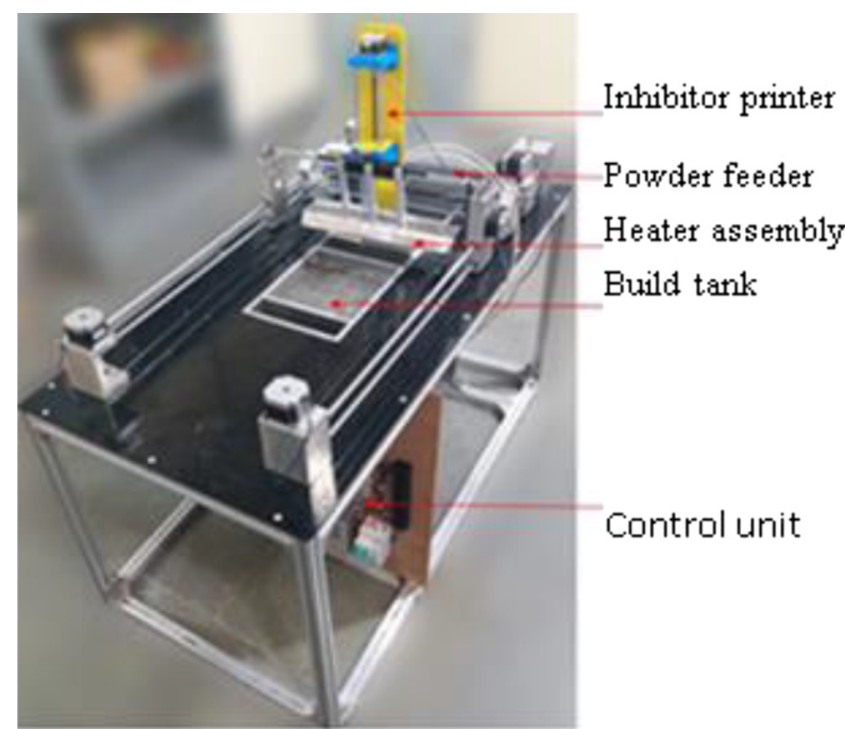

Fig. 1. SIS machine.

$200 \mathrm{~mm} \times 250 \mathrm{~mm} \times 200 \mathrm{~mm}$. The inhibitor depositor defines the part profile through printing liquid inhibitor solution on the selected region of the powder bed. Finally, the entire powder layer is sintered using an infrared heating element, and ceramic bed heater is used to heat the build platform to maintain predefine temperature. These processes are required to be repeated until the entire part is completed. During the development of custom made SIS system, various challenges were encountered in terms of precise manufacturing, assembly, and actuation of build and feed tanks. The control of bed temperature, heater and precise delivery of inhibitor were created major issues, and they were sorted out. In addition, the developed SIS machine is characterized only for few thermoplastic materials where polyamide 12 is not one of them. Hence, characterizing the process for polyamide 12 material which is specifically custom-made for the SLS process was one of the difficult challenges faced while conducting the present study. Many sintering studies for PA12 to avoid curling, burning and melting were performed to obtain effective sintering of powder particles.

Moreover, the identification of the best inhibitor material that works for PA12 material and its composition in the solution were needed, and various iterations were performed to finalize it. More inhibition trials also conducted to obtain precise profile. Similar to other AM systems, part fabrication process in SIS system as shown in Figure 2, began with creating its three dimensional (3D) CAD model. CATIA V5-R20 solid modeling software was used to create the part model and converted into stereolithographic (.stl) file format. The model was then sliced into thin layers using Slic3r software. The Slic3r software also generated the G-codes for each sliced layers. These G-codes then uploaded to the SIS machine controller using Pronterface firmware so by using these G-codes the controller drives the various components of the machine so as to print the required parts as per the design specifications. Test specimens, given in Figure 3, were then fabricated as per the ASTM standard [33] from PA 12 for 

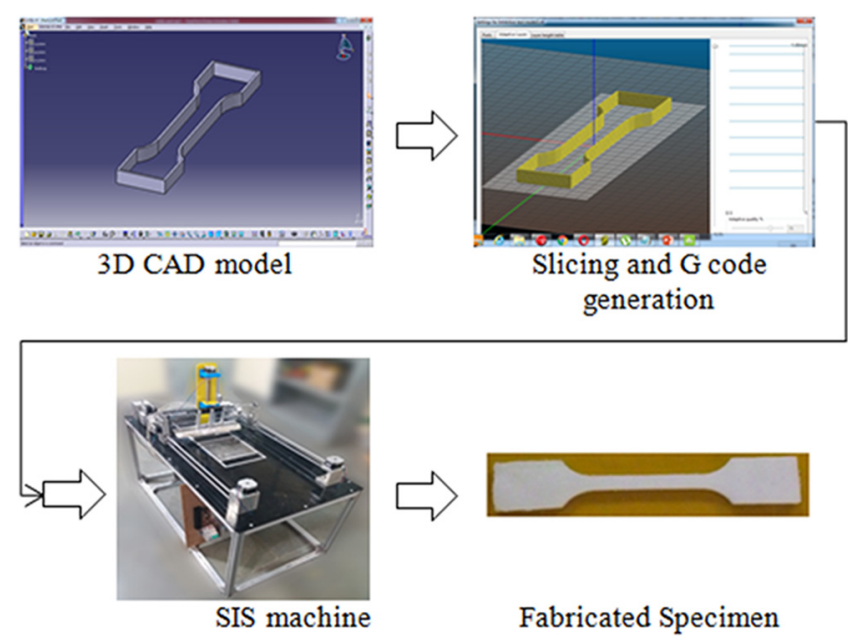

Fig. 2. SIS part fabrication procedure.

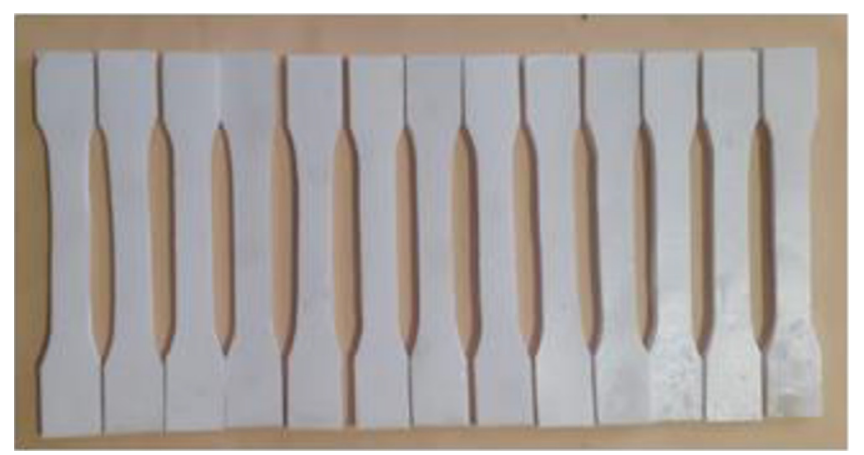

Fig. 3. Fabricated SIS specimen based on ASTM D7791.

29 experimental runs at different combinations of processing parameters. During specimen fabrication, the hold values were, build platform temperature (100), printer nozzle diameter $(0.26 \mathrm{~mm})$ and printer nozzle stand-off $(5 \mathrm{~mm})$.

\subsection{Fatigue testing}

In accordance with the ASTM standard for testing the fatigue properties of plastic material was followed to conduct the fatigue test [33]. The fatigue test were conducted using MTS Servo Hydraulic Testing Machine, Model: IN-DF300 at room temperature. During testing, the samples were subjected to fully reversed constant amplitude stresses at a frequency of $3 \mathrm{~Hz}$. The mean stress of the cyclical loading was zero and loading ratio, $R$-ratio was -1 . For each set of experimental runs, the maximum stress amplitudes were determined prior to conducting the fatigue test using the tensile strength tests. Having determined the starting stress amplitude; the remaining stress amplitudes were calculated from the ultimate tensile strength. The amplitude stresses were varied from $40 \%$ to $85 \%$ of the ultimate tensile strength. Fatigue tests were carried out based on the FKM guideline [34,35]. The tests were when the specimens fractured or when the number of loading cycles exceeded one million. For each experimental runs, four levels of stress variations were carried out to achieve adequate number of data for constructing $\mathrm{S}-\mathrm{N}$ diagrams. For each stress amplitude, three specimens were tested and the average of the number of cycles to failure was considered for constructing the $\mathrm{S}-\mathrm{N}$ curve. The different combinations of datasets and the corresponding measured values are given in Table 3 .

\subsection{Response surface}

In the manufacturing process, RSM is a widely used technique to design and analyze experiments [36]. It is a combination of statistical, mathematical and optimization tool which is used for designing experiments and analyzing, modeling and optimizing responses variables [37-40]. In RSM, the relationship between response variables and process parameters is mathematically expressed as:

$$
y=f\left(x_{1}, x_{2}, \ldots, x_{k}\right)+\varepsilon .
$$

In this study, the four process variables with three levels were empirically related with the process response variable, fatigue strength using second-order model. The general second-order response function of the response surface methodology is given by,

$$
\begin{aligned}
y= & \beta_{0}+\sum_{i-1}^{k} \beta_{i} x_{i}+\sum_{i=1}^{k} \beta_{i i} x_{i} 2 \\
& +\sum_{i, j=1, i \neq j}^{k} \beta_{i j} x_{i} x_{j}+\varepsilon
\end{aligned}
$$

where $y$ denotes response variable, $\beta_{0}$ is the model constant; $x_{i}$ and $x_{j}$ are the process parameters; $\beta_{i}$ is the coefficient of the main term; $\beta_{i i}$ is the coefficient of the square term; $\beta_{i j}$ is the coefficient of the interaction term; $K$ indicates the number of factors considered and $\varepsilon$ is statistical error.

\section{Results and discussions}

The experimental fatigue strength values of PA 12, obtained from the experimental investigation given in Table 3, were analyzed using Minitab 18 statistical software to generate mathematical model that relates process variables with the response variables of interest.

\subsection{Empirical response surface analysis}

The experimentally measured data were analyzed using Minitab 18 statistical software and regression response surface model was developed. Second-order response surface model was fitted for the fatigue strength to reduce the error between response value predicted by the model and the measured value. In order to determine the adequacy of the model by examining the main effect as well as the interaction effect of factors, analysis of variance (ANOVA) was conducted. The prediction capability of the model was improved by evaluating the statistical significance of each term in the ANOVA table and the method of backward elimination was implemented based on $95 \%$ 
Table 3. Experimental runs and the corresponding experimental fatigue strength result.

\begin{tabular}{|c|c|c|c|c|c|}
\hline Run & $\begin{array}{l}\text { A: Layer } \\
\text { thickness } \\
(\mathrm{mm})\end{array}$ & $\begin{array}{l}\text { B: Heater } \\
\text { temperature } \\
\left({ }^{\circ} \mathrm{C}\right)\end{array}$ & $\begin{array}{l}\text { C: Heater } \\
\text { feed rate } \\
(\mathrm{mm} / \mathrm{sec})\end{array}$ & $\begin{array}{l}\text { D: Printer } \\
\text { feed rate } \\
(\mathrm{mm} / \mathrm{min})\end{array}$ & $\begin{array}{l}\text { Fatigue } \\
\text { strength } \\
\text { (MPa) }\end{array}$ \\
\hline 1 & 0.4 & 230 & 3.5 & 110 & 13.81 \\
\hline 2 & 0.3 & 230 & 3 & 120 & 13.33 \\
\hline 3 & 0.2 & 230 & 3.5 & 110 & 12.86 \\
\hline 4 & 0.3 & 230 & 3.25 & 110 & 16 \\
\hline 5 & 0.4 & 220 & 3.25 & 110 & 17.15 \\
\hline 6 & 0.3 & 240 & 3.25 & 110 & 14.375 \\
\hline 7 & 0.3 & 240 & 3.5 & 110 & 11.66 \\
\hline 8 & 0.3 & 240 & 3 & 110 & 12.15 \\
\hline 9 & 0.3 & 230 & 3.5 & 120 & 13.1 \\
\hline 10 & 0.3 & 230 & 3.25 & 110 & 16.36 \\
\hline 11 & 0.3 & 220 & 3.25 & 120 & 15.43 \\
\hline 12 & 0.3 & 220 & 3.25 & 100 & 16.63 \\
\hline 13 & 0.4 & 230 & 3 & 110 & 12.86 \\
\hline 14 & 0.3 & 240 & 3.25 & 100 & 13.33 \\
\hline 15 & 0.3 & 230 & 3.5 & 100 & 12.73 \\
\hline 16 & 0.4 & 230 & 3.25 & 100 & 14.88 \\
\hline 17 & 0.3 & 230 & 3.25 & 110 & 15.83 \\
\hline 18 & 0.2 & 230 & 3 & 110 & 16.2 \\
\hline 19 & 0.3 & 220 & 3.5 & 110 & 13.53 \\
\hline 20 & 0.3 & 230 & 3.25 & 110 & 15.6 \\
\hline 21 & 0.3 & 230 & 3.25 & 110 & 15.5 \\
\hline 22 & 0.3 & 220 & 3 & 110 & 15.71 \\
\hline 23 & 0.3 & 240 & 3.25 & 120 & 13.93 \\
\hline 24 & 0.3 & 220 & 3.25 & 110 & 15.68 \\
\hline 25 & 0.3 & 230 & 3.25 & 120 & 15.93 \\
\hline 26 & 0.2 & 230 & 3.25 & 100 & 16.78 \\
\hline 27 & 0.4 & 230 & 3.25 & 120 & 15.01 \\
\hline 28 & 0.3 & 230 & 3 & 100 & 15.32 \\
\hline 29 & 0.4 & 240 & 3.25 & 110 & 12.46 \\
\hline
\end{tabular}

confidence level and also $p$-value test. The reduced final mathematical model, given in equation (4) was obtained through conducting regression analysis several times.

$$
\begin{aligned}
y= & -357+128.6 A+2.394 B+121.7 C \\
& -1.821 D-0.00695 B^{2}-31.08 C^{2} \\
& -1.192 A B+42.90 A C+0.169 B C \\
& +0.0045 B D+0.236 C D
\end{aligned}
$$

where $Y$ is the predicted fatigue strength, and $A$ is layer thickness, $B$ is heater temperature, $C$ is heater feed rate and $D$ is printer feed rate. The synergetic and antagonistic effects of predictor variables are indicated by the sign of the coefficients. The magnitude of $p$-value in the ANOVA table (Tab. 4), signifies whether a term in the proposed model is significant. The $p$-value smaller than 0.05 indicates that the independent parameter is statistically significant [41]; statistically insignificant terms have $p$-values $\geq 0.05$. Consequently, these parameters need to be eliminated from the regression fit model. Therefore, as can be seen from the table, the probability values of $A$ (layer thickness), $B$ (heater temperature), and $C$ (heater feed rate) are smaller than 0.05 ; thus, their influence on the fatigue strength is significant. Similarly, the $p$-values of the squares of parameters $B$ and $C$ were less than 0.05 and hence they had nonlinear effects on the response variable. In addition, the ANOVA result shows that interaction terms $\mathrm{A}^{*} \mathrm{~B}, \mathrm{~A}^{*} \mathrm{C}, \mathrm{B} * \mathrm{C}, \mathrm{B}^{*} \mathrm{D}$ and $\mathrm{C}^{*} \mathrm{D}$ affect the fatigue strength significantly with p-vales $0.001,0.000,0.033$, 0.025 and 0.005 respectively.

However, $p$-value for the independent parameter $D$ (printer feed rate) was 0.065 , hence the main effect of this parameter is negligible. Likewise, square terms of parameter $A$ and $D$, and interaction terms $A D$ are insignificant terms to the fitted model with p-values 0.067 , 0.795 and 0.217 respectively. Moreover, the effect of squares of parameters $A$ and $D$, and interaction term, $\mathrm{A} * \mathrm{D}$ were negligible with $p$-values $0.795,0.067$ and 0.217 respectively. Therefore, after removing these terms from 
Table 4. Initial ANOVA for fatigue strength.

\begin{tabular}{lrrrrll}
\hline Source & DF & Sum of squares & Mean Squares & $F$-Value & $P$-Value & Decision \\
\hline Model & 14 & 66.6498 & 4.7607 & 37.21 & 0.000 & Statistically significant \\
A & 1 & 2.2126 & 2.2126 & 17.29 & 0.001 & Statistically significant \\
B & 1 & 13.3056 & 13.3056 & 104.00 & 0.000 & Statistically significant \\
C & 1 & 5.1745 & 5.1745 & 40.44 & 0.000 & Statistically significant \\
D & 1 & 0.5134 & 0.5134 & 4.01 & 0.065 & Negligibly small \\
$\mathrm{A}^{*} \mathrm{~A}$ & 1 & 0.0090 & 0.0090 & 0.07 & 0.795 & Negligibly small \\
$\mathrm{B}^{*} \mathrm{~B}$ & 1 & 3.0281 & 3.0281 & 23.67 & 0.000 & Statistically significant \\
$\mathrm{C}^{*} \mathrm{C}$ & 1 & 24.7528 & 24.7528 & 193.47 & 0.000 & Statistically significant \\
$\mathrm{D}^{*} \mathrm{D}$ & 1 & 0.5034 & 0.5034 & 3.93 & 0.067 & Negligibly small \\
$\mathrm{A}^{*} \mathrm{~B}$ & 1 & 2.3661 & 2.3661 & 18.49 & 0.001 & Statistically significant \\
$\mathrm{A}^{*} \mathrm{C}$ & 1 & 4.6010 & 4.6010 & 35.96 & 0.000 & Statistically significant \\
$\mathrm{A}^{*} \mathrm{D}$ & 1 & 0.2141 & 0.2141 & 1.67 & 0.217 & Negligibly small \\
$\mathrm{B}^{*} \mathrm{C}$ & 1 & 0.7140 & 0.7140 & 5.58 & 0.033 & Statistically significant \\
$\mathrm{B}^{*} \mathrm{D}$ & 1 & 0.8100 & 0.8100 & 6.33 & 0.025 & Statistically significant \\
$\mathrm{C}^{*} \mathrm{D}$ & 1 & 1.3924 & 1.3924 & 10.88 & 0.005 & Statistically significant \\
Error & 14 & 1.7912 & 0.1279 & & & Negligibly small \\
Lack-of-Fit & 10 & 1.3235 & 0.1323 & 1.13 & 0.492 & Statistically significant \\
Pure Error & 4 & 0.4677 & 0.1169 & & & \\
Total & 28 & 68.4410 & & & & \\
\hline
\end{tabular}

the full model (except parameter $D$, due to its considerable interactive effect with other parameters such as $B$ and $C$ ) another ANOVA was conducted. Table 5 shows the final ANOVA result generated omitting the insignificant terms based on the first ANOVA result. Table 5 presents the ANOVA results on which the final reduced regression response surface model given in equation (4) is obtained. As seen from Table 5 , all terms are statistically significant to the fitted model except parameter $D$ (Printer feed rate). Yet, it is still kept in the proposed prediction model because of its interaction with factor B (heater temperature) and $C$ (heater feed rate) that had considerable influence on fatigue strength. It is also seen from the ANOVA table that the $p$-value for the Lack-of-Fit is 0.41 . Thus, the regression response surface equation satisfactorily fits the data. Another ANOVA statistics values that describe about the model adequacy for predicting response are the standard deviation and $R$ squared values.

The standard deviation between the measured and predicted fatigue strength is 0.39 . This value is low that it indicates that the generated model is adequate in predicting the response variable. However, $R$ squared value close to $1(100 \%)$ can predict the response variable value with less error. An $R$-squared value of the reduced regression equation is $96.28 \%$, and it indicates that the proposed model returns a better estimate of the response variable value.

Moreover, in order to additionally verify the statistical significance of the independent factors, Pareto chart and the normal plot of the standardized effect given in Figures 4 and 5 were used. The plots graphically indicate predictor terms $D, A A, D D$, and $A D$, are insignificant and should be eliminated from the regression second-order fitted model. Further justification of the independent parameters' effect on the fatigue strength is given using main effect plot shown in Figure 6.

It is seen from the graph that fatigue strength is inversely proportional to the layer thickness setting and heater temperature, whereas, the effect of heater feed rate on the fatigue strength is nonlinear. Fatigue strength improves as we move closer to the middle value of the experimental range of the heater feed rate settings. On the other hand, although printer feed rate $(D)$ affects the process insignificantly, fatigue strength seems to be slightly larger for lower setting value.

\subsection{Analysis of residuals of regression}

The normality of the measured values can be tested using the normal probability plot [42]. In an effort to examine the fitted second order model and to modify it, residual analysis was conducted. Mathematically, residual is defined as,

$$
e=y-m
$$

where $y$ is the measured value, $m$ is the estimated value, and $e$ is residual or error. The normal probability plot of residuals given in Figure 7 follows approximately a straight line. It shows the regression fitted the measured fatigue strength satisfactorily. This also indicates the normality of the experimentally collected data. In addition, the histogram of the residuals (Fig. 8) indicates the errors are close to normally distributed about the zero mean which depicts that the regression model fitted the data well. Figure 9 shows the residuals versus fits plot for 
Table 5. Final ANOVA for fatigue strength.

\begin{tabular}{lrrrrll}
\hline Source & DF & Sum of squares & Mean squares & $F$-value & $P$-value & Decision \\
\hline Model & 11 & 65.8964 & 5.9906 & 40.02 & 0.000 & Statistically significant \\
$\mathrm{A}$ & 1 & 3.0261 & 3.0261 & 20.22 & 0.000 & Statistically significant \\
$\mathrm{B}$ & 1 & 13.3056 & 13.3056 & 88.89 & 0.000 & Statistically significant \\
$\mathrm{C}$ & 1 & 5.1745 & 5.1745 & 34.57 & 0.000 & Statistically significant \\
$\mathrm{D}$ & 1 & 0.4508 & 0.4508 & 3.01 & 0.101 & Negligibly small \\
$\mathrm{B}^{*} \mathrm{~B}$ & 1 & 3.3117 & 3.3117 & 22.13 & 0.000 & Statistically significant \\
$\mathrm{C}^{*} \mathrm{C}$ & 1 & 25.4646 & 25.4646 & 170.12 & 0.000 & Statistically significant \\
$\mathrm{A}^{*} \mathrm{~B}$ & 1 & 2.3661 & 2.3661 & 15.81 & 0.001 & Statistically significant \\
$\mathrm{A}^{*} \mathrm{C}$ & 1 & 4.6010 & 4.6010 & 30.74 & 0.000 & Statistically significant \\
$\mathrm{B}^{*} \mathrm{C}$ & 1 & 0.7140 & 0.7140 & 4.77 & 0.043 & Statistically significant \\
$\mathrm{B}^{*} \mathrm{D}$ & 1 & 0.8100 & 0.8100 & 5.41 & 0.033 & Statistically significant \\
$\mathrm{C}^{*} \mathrm{D}$ & 1 & 1.3924 & 1.3924 & 9.30 & 0.007 & Statistically significant \\
Error & 17 & 2.5446 & 0.1497 & & & Negligibly small \\
Lack-of-Fit & 13 & 2.0769 & 0.1598 & 1.37 & 0.414 & Statistically significant \\
Pure Error & 4 & 0.4677 & 0.1169 & & & \\
Total & 28 & 68.4410 & & & & \\
\hline
\end{tabular}

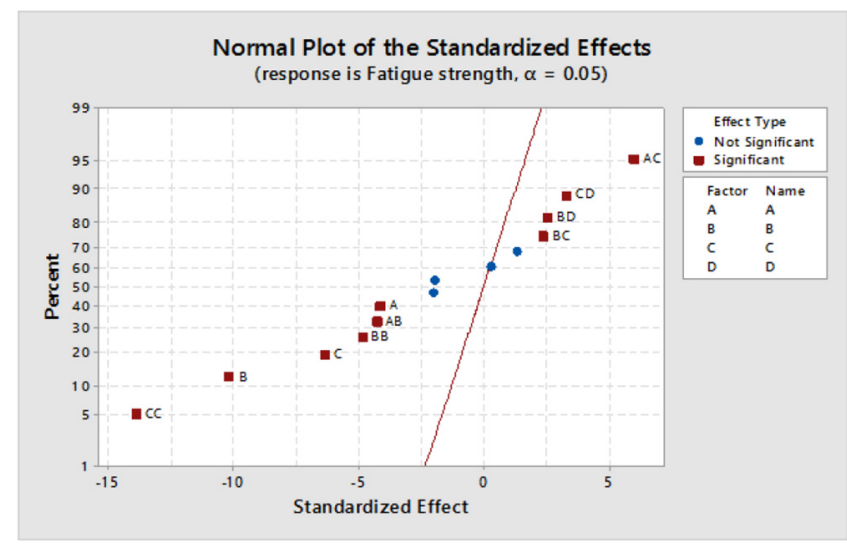

Fig. 4. Normal plot standardized effects.

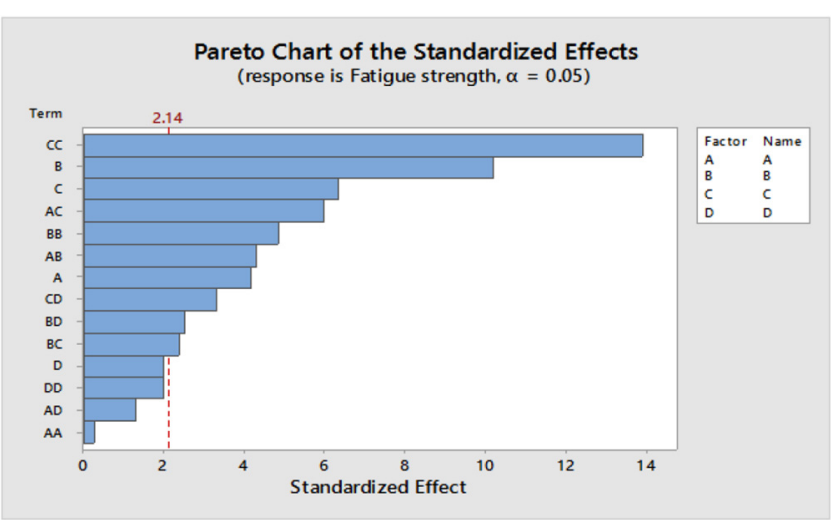

Fig. 5. Pareto chart of standardized effects.

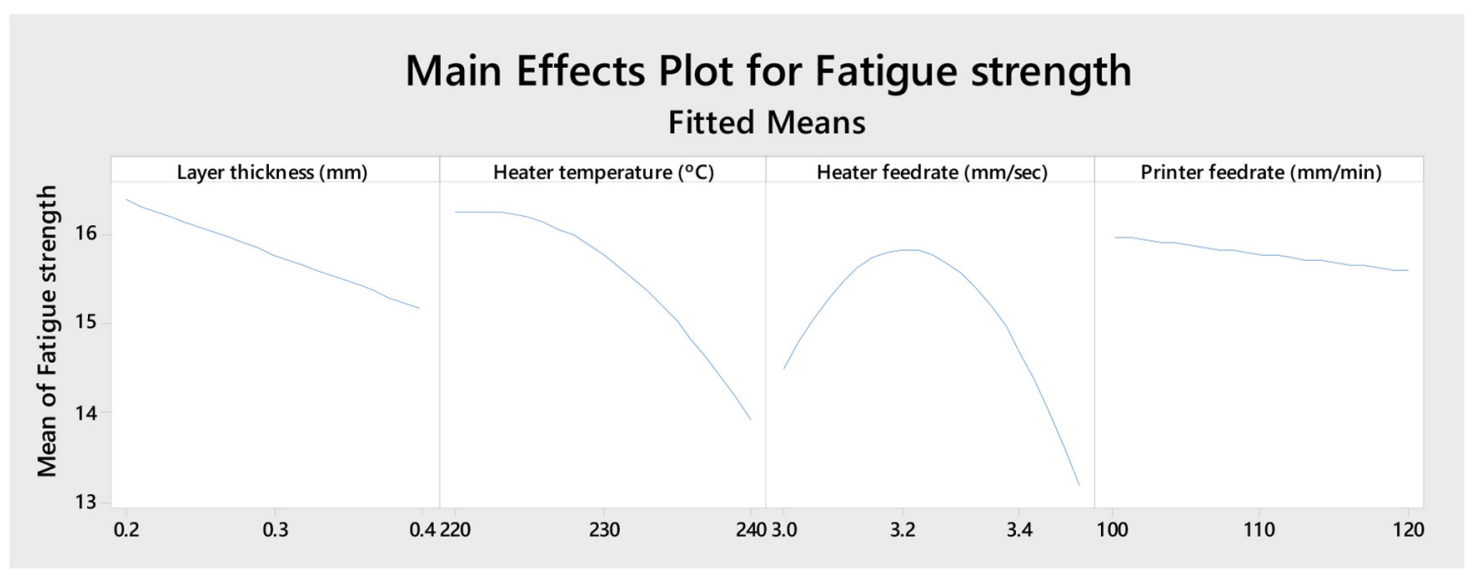

Fig. 6. Main effect of SIS process variables on fatigue strengths of PA12. 


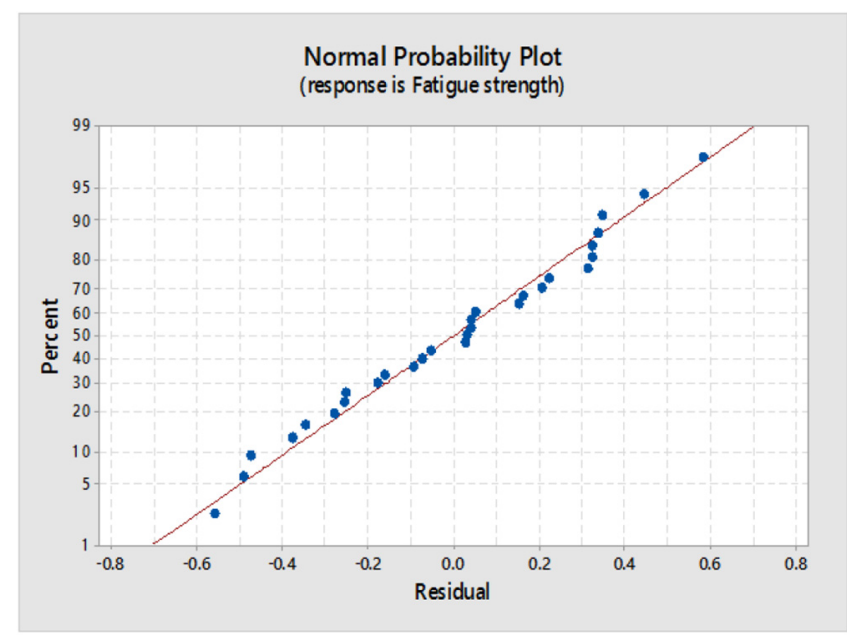

Fig. 7. Normal plot standardized effects.

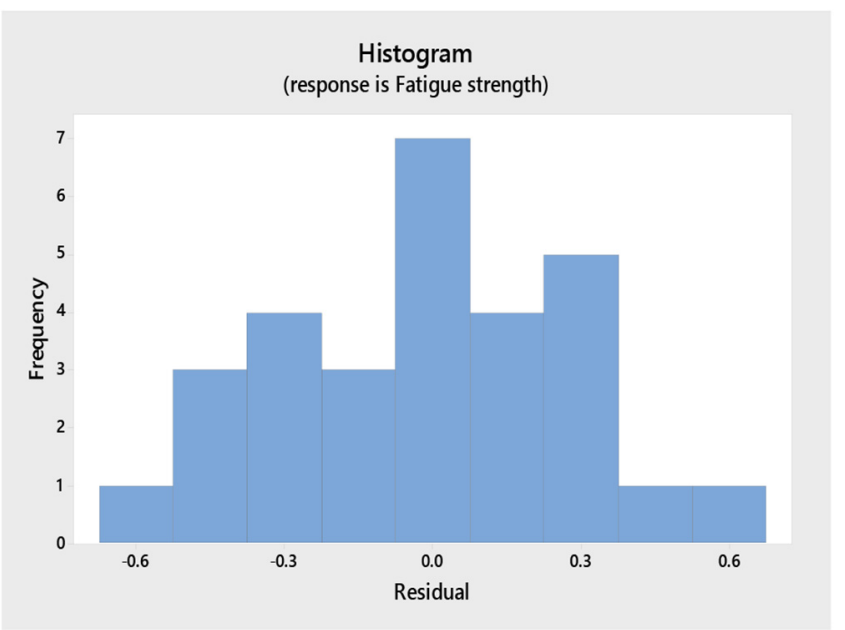

Fig. 8. Histogram of residuals.

the corresponding fitted response surface model developed after eliminating the identified insignificant factors. From the plot, it is seen that the residuals are arbitrarily dispersed about zero which signifies the eliminated terms had not caused an undesired effect on predicting ability of the proposed model. From both the plots (Figs. 9 and 10), it can be depicted that errors are randomly scattered about zero and the magnitude of the variance fall within \pm 0.75 . Therefore, from the residual analysis, it can be deduced that the developed model is appropriate for predicting response.

\subsection{Contour plots of the response surface model}

The relationship between process variables and their effect on the fatigue strength is explained using contour plots. It is a graphical representation of three-dimensional data in two-dimensional plane [43]. Therefore, to analyze the impact of any two interacting parameters on the fatigue

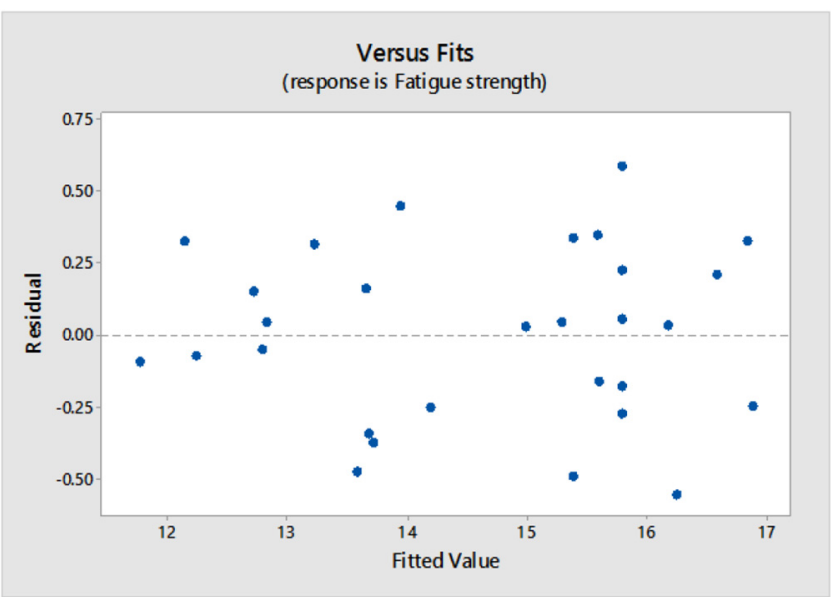

Fig. 9. Normal probability plots of residuals.

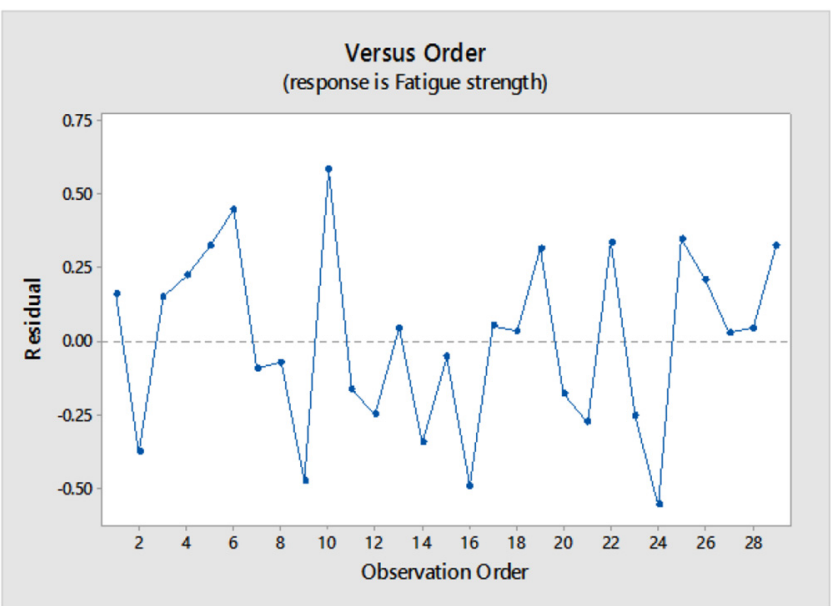

Fig. 10. Plot for residual versus data order.

strength of the SIS fabricated PA12 part, response contour plots indicated in Figures 11-14 were constructed by holding the settings of remaining parameters at their middle value. As seen from Figure 11, optimum fatigue strength is achieved at low settings of layer thickness and the heater temperature because better layer attachment is achieved at lower layer thickness [44]. Low layer thickness enables the heat energy to be transferred throughout the powder bed in the given period of time and fuse it. On the contrary, when layer thickness increases the heat distribution across the thickness may not be uniform and poor consolidation may occur. In addition, for large layer thickness, the number of voids and pores increases which leads to lower the fatigue strength. The result also shows lower heater energy around $220^{\circ} \mathrm{C}$ was sufficient enough to fuse powder particles as well as to create necessary bonding between the successive layers. At higher heater energy, more heat energy is transferred into the powder bed which will decompose the polymer and produces gas that leads to porosity [45]. Similarly, Figure 12 shows the impact of 


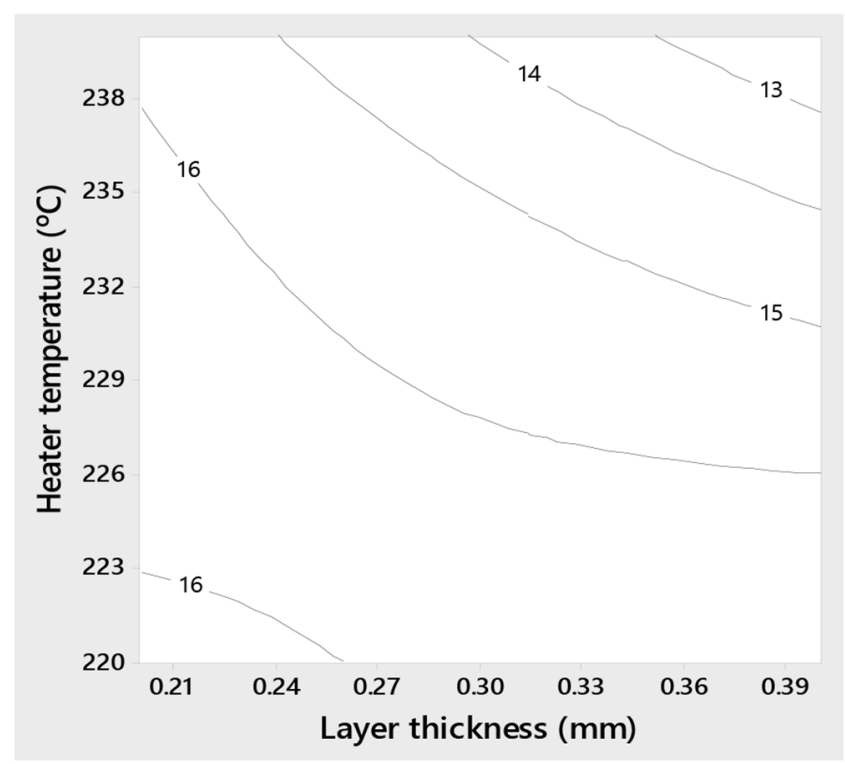

Fig. 11. Contour plot of fatigue strength versus layer thickness and heater temperature.

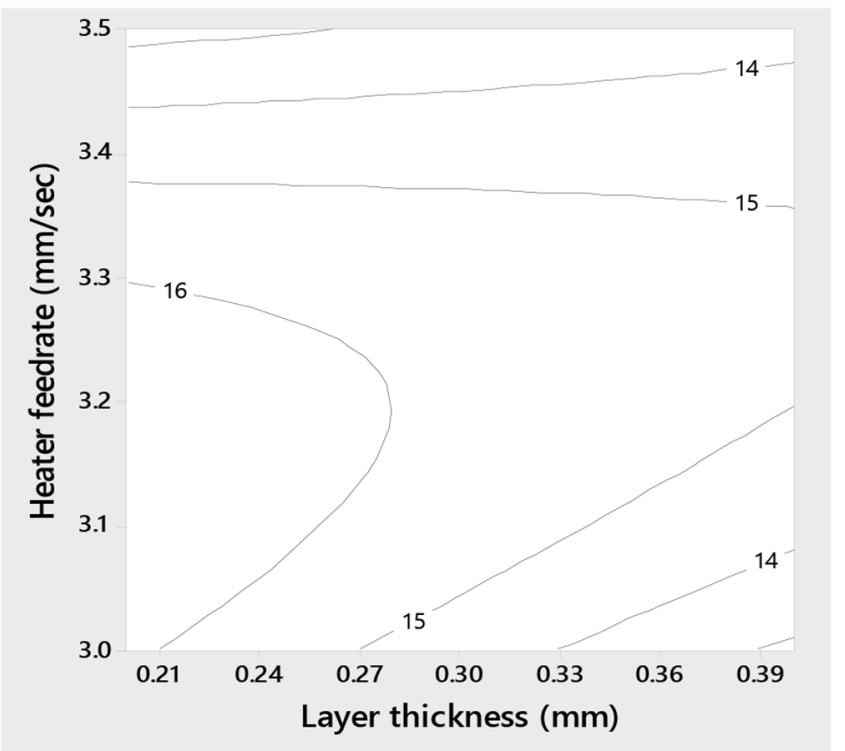

Fig. 12. Contour plot of fatigue strength versus layer thickness and heater feed rate.

the interaction of layer thickness and heater feed rate on the fatigue property of SIS parts. It is evident from the plot that fatigue strength was high for lower layer thickness and for heater feed rate setting between $3.1 \mathrm{~mm} / \mathrm{sec}$ to $3.2 \mathrm{~mm} / \mathrm{sec}$. At higher feed rate the powder bed cannot get enough time to absorb sufficient amount of heat energy that fuse the powder particles together and also to create bonding between layers. As a result, the fatigue strength was lower at higher heater feed rate [13].

Figure 13 illustrates the interaction effect of heater temperature and heater feed rate on fatigue strength. From the figure, it is clearly seen that maximum fatigue property was achieved for heater temperature from $220{ }^{\circ} \mathrm{C}$ to $230{ }^{\circ} \mathrm{C}$

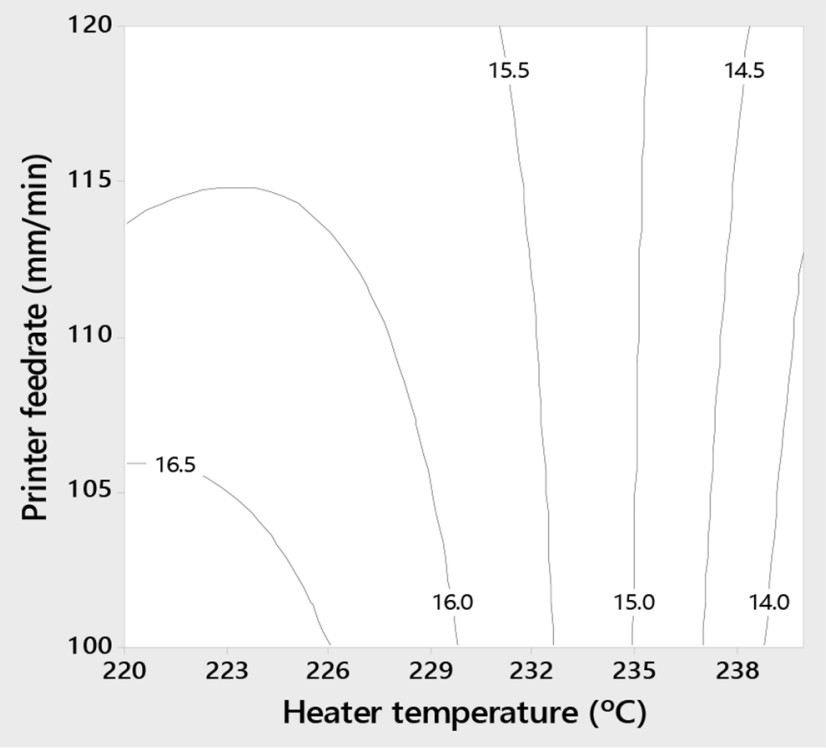

Fig. 13. Contour plot of fatigue strength versus heater temperature and heater feed rate.

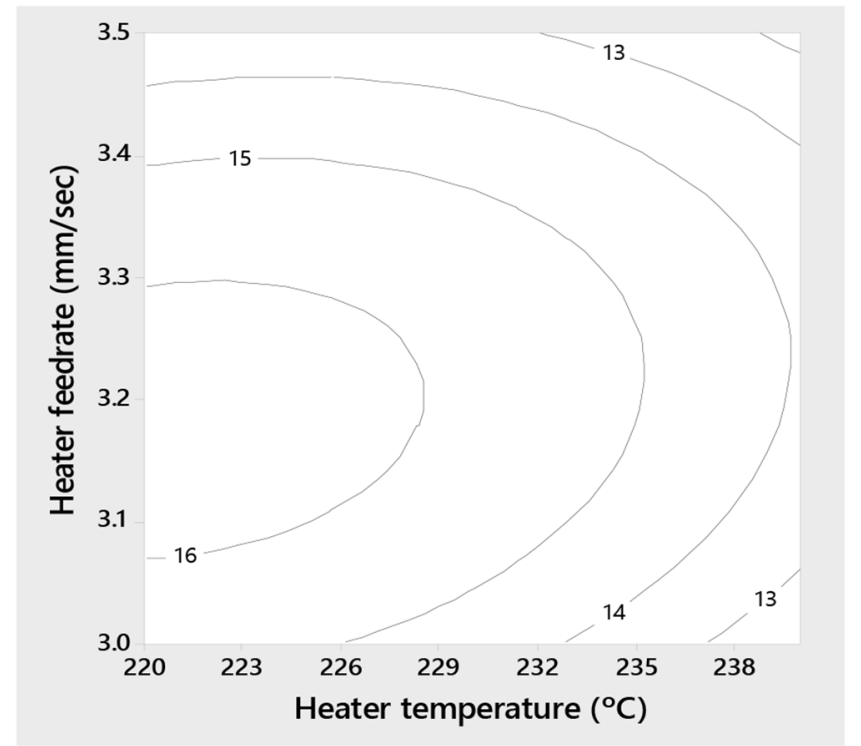

Fig. 14. Contour plot of fatigue strength versus heater temperature and printer feed rate.

and heater feed rate from $3.1 \mathrm{~mm} / \mathrm{sec}$ to $3.2 \mathrm{~mm} / \mathrm{sec}$. Finally, interaction effect of the heater feed rate and the printer feed rate on the response variable is also presented in Figure 14. It indicates that optimum fatigue strength property was obtained at heater feed rate from $3.1 \mathrm{~mm} / \mathrm{sec}$ to $3.2 \mathrm{~mm} / \mathrm{sec}$ and lower range of printer feed rate setting.

\subsection{Microstructure analysis}

The microstructure of part provides fundamental information to comprehend how part characteristics are affected by process parameters. Figure 15a and b shows the scanning 


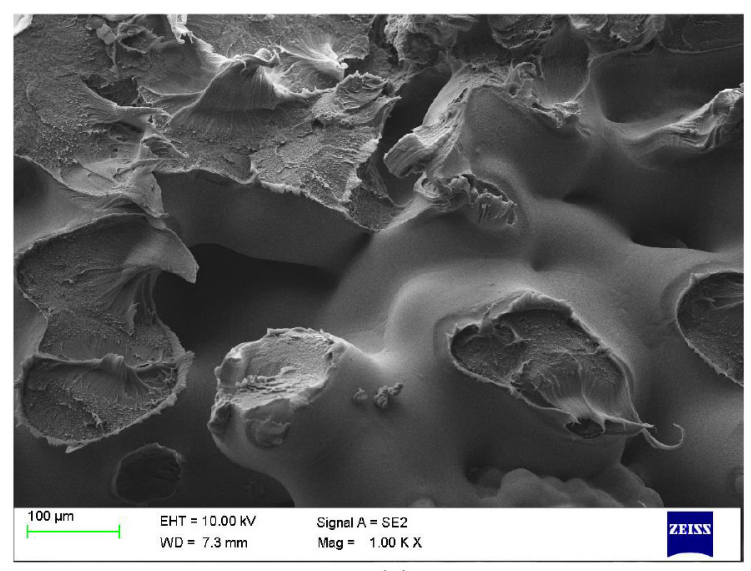

(a)

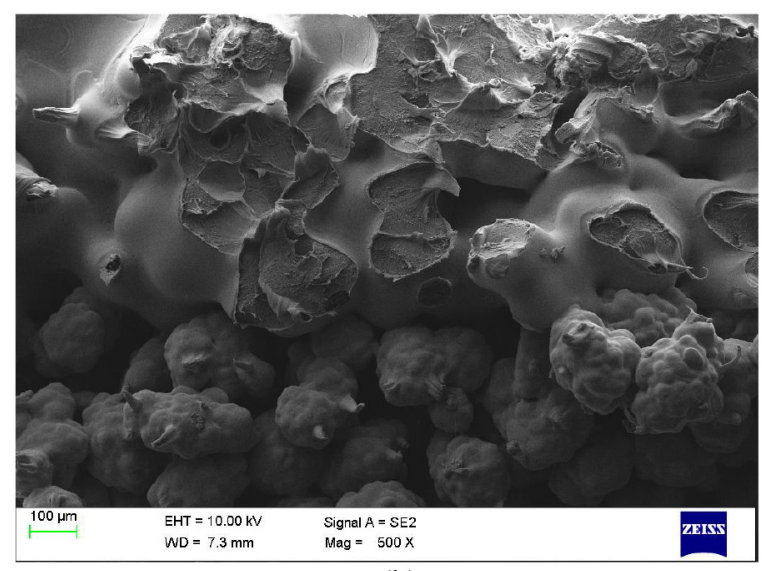

(b)

Fig. 15. SEM images of SIS parts fabricated at heater temperature of $220^{\circ} \mathrm{C}$, heater feed rate of $3 \mathrm{~mm} / \mathrm{s}$, and printer feed rate of $100 \mathrm{~mm} / \mathrm{min}$. (a) Layer thickness of $0.2 \mathrm{~mm}$. (b) Layer thickness of $0.4 \mathrm{~mm}$.

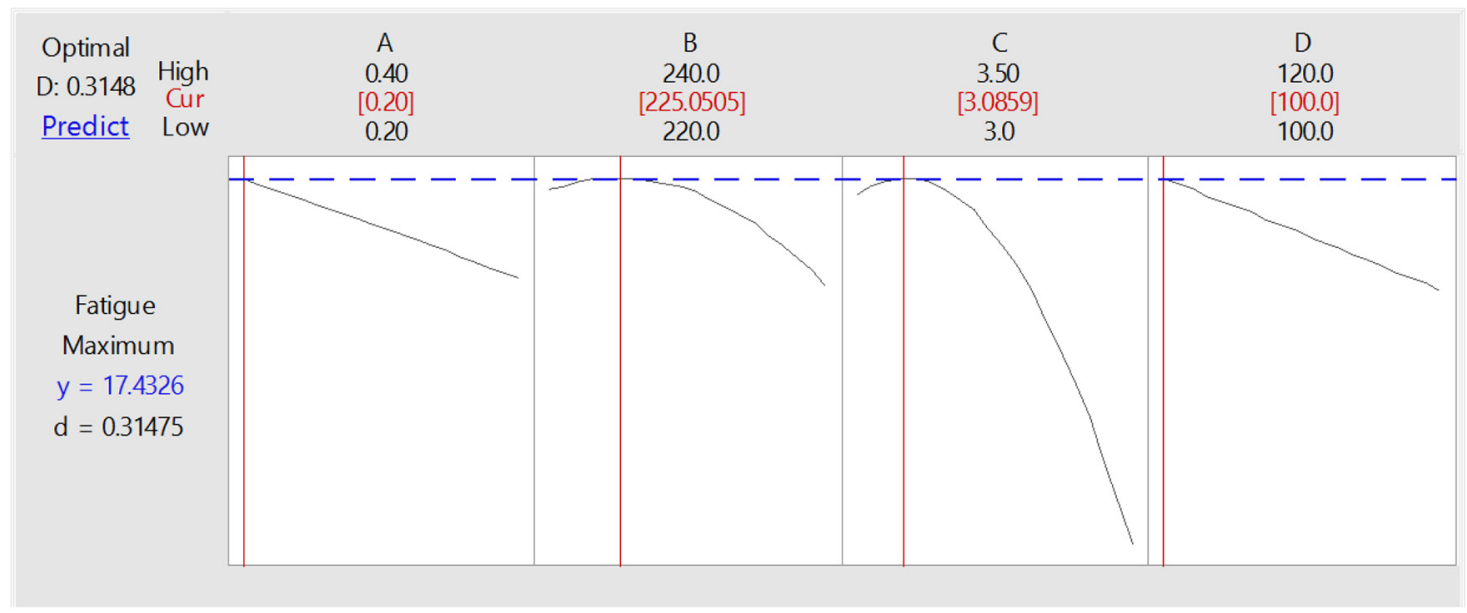

Fig. 16. SIS process variable setting curve for optimum fatigue strength value.

electron microscope (SEM) images of surface fractured by fatigue loading for various layer thicknesses. Figure 15a indicates the microstructure of the specimen fabricated with layer thickness of $0.2 \mathrm{~mm}$. It demonstrates powder particles are properly fused throughout the thickness which tells us that for low layer thickness the heat energy from the source was distributed uniformly, and it was adequate for sintering the entire powder volume. Therefore, it can be deduced that lower thickness powder bed absorbs sufficient heat energy for sintering to occur. On the other hand, for layer thickness of $0.4 \mathrm{~mm}$, the sintering was found to be improper as seen in Figure 15b. Quality of the top and bottom of the powder bed appears to be non-uniform. From the top of the layer up to halfway through the thickness, particles appeared to have sintered properly, while the powders in the remaining half part was not sintered well. For large layer thickness, the heat energy absorbed by the powder bed was not uniformly distributed across the thickness of the powder layer due to unnecessary dissipation. As a result, it was seen some unfused powders at the bottom side of the layer. These unsintered powder particles in the part would cause stress concentration and weaken the part in terms of carrying mechanical load. Due to this phenomenon, the part fabricated with $0.4 \mathrm{~mm}$ layer thickness supported lower fatigue load than part made with $0.2 \mathrm{~mm}$ layer thickness.

\subsection{Optimization of process parameters}

The optimal SIS process parameter settings that maximize the fatigue strength of PA 12 parts were identified using Minitab 18 statistical software response optimizer. Figure 16 is the optimization plot that illustrates the various combinations of parameter settings. It is evident that the best settings of parameters for achieving maximum fatigue strength of PA 12 parts were layer thickness of $0.2 \mathrm{~mm}$, heater temperature of $225{ }^{\circ} \mathrm{C}$, heater feed rate of $3.09 \mathrm{~mm} / \mathrm{sec}$, and printer feed rate of $100 \mathrm{~mm} / \mathrm{min}$. At these setting values, the predicted optimum fatigue strength was $17.43 \mathrm{MPa}$ with a desirability score of 1 . 
Table 6. Verification experiment.

\begin{tabular}{lllllll}
\hline $\begin{array}{l}\text { Layer } \\
\text { thickness } \\
(\mathrm{mm})\end{array}$ & $\begin{array}{l}\text { Heater } \\
\text { temperature } \\
\left({ }^{\circ} \mathrm{C}\right)\end{array}$ & $\begin{array}{l}\text { Heater } \\
\text { feed rate } \\
(\mathrm{mm} / \mathrm{sec})\end{array}$ & $\begin{array}{l}\text { Printer } \\
\text { feed rate } \\
(\mathrm{mm} / \mathrm{min})\end{array}$ & $\begin{array}{l}\text { Fatigue } \\
\text { strength (MPa) }\end{array}$ & $\begin{array}{l}\text { Fatigue } \\
\text { Predicted value } \\
(\mathrm{MPa})\end{array}$ & $\begin{array}{l}\text { Fatigue } \\
\text { Measured }\end{array}$ \\
\hline 0.2 & 225.05 & 3.09 & 100 & 17.43 & 17.93 & 0.05 \\
strength \\
$(\mathrm{MPa})$ \\
{$[26-28]$}
\end{tabular}

To experimentally verify the estimated optimum value, five specimens were fabricated at the suggested optimal combination parameter settings, and their fatigue strength was measured. From the test, the average fatigue strength value achieved was 17.93MPa. The comparison of the measured and the predicted values are given in Table 6 , and it shows that the difference between the measured and predicted values is 0.62 . Moreover, the value achieved in this work is found to be comparable with the fatigue strength of PA 12 parts made by SLS process which is $18 \mathrm{MPa}$ [26-28].

\section{Conclusion}

In this study, fatigue property of an SIS fabricated polyamide 12 part has been investigated using the BoxBehnken design response surface approach. The SIS process parameters were optimized to maximize the fatigue strength. Based on the study the subsequent deductions have been made.

- Based on Box-Behnken design, the fatigue strength for 29 datasets was tested experimentally and the prediction model was obtained through fitting second-order response surface model to the measured data. The fatigue strength predicted by the generated model was close to the experimentally measured value (with $R$ squared value of $97.38 \%$ ).

- ANOVA results showed that the printer feed rate has insignificant effect on the fatigue strength of SIS printed parts. Whereas, the effect of the remaining three variables is significant.

- Fatigue property increases linearly with decreasing in layer thickness and heater temperature. However, the optimum heater feed rate setting to maximize the fatigue strength is at $3.2 \mathrm{~mm} / \mathrm{sec}$.

- Although the linear term of the printer feed rate is statistically insignificant, its interaction with the heater temperature and heater feed rate is considerably high.

- For the SIS process variables of $0.2 \mathrm{~mm}$ layer thickness, $225^{\circ} \mathrm{C}$ heater temperature, $3.01 \mathrm{~mm} / \mathrm{sec}$ heater feed rate, and $100 \mathrm{~mm} / \mathrm{min}$ printer feed rate, an optimum fatigue property of $17.43 \mathrm{MPa}$ has been achieved for SIS fabricated parts.

- Optimized parameters settings were experimentally validated, and fatigue strength of $17.93 \mathrm{MPa}$ was found which is in good agreement with the predicted value with a variance of approximately 0.50 .
- Through optimization, the fatigue strength was improved by more than $4.5 \%$ from $17.15 \mathrm{MPa}$ to $17.93 \mathrm{MPa}$.

- The optimal fatigue strength achieved by an SIS part is approximately equal to the fatigue strength of an SLS fabricated part found in the literature for the similar material which is $18 \mathrm{MPa}$.

The present work focused on fabrication of components using SIS system from polymer powders. However, the demand for functional 3D printed metal parts by the aerospace and automobile industries is on the rise. There are not much research works being carried out on the development of SIS system for fabricating functional near net shape components from metal powders. In the future, attempts can be made to develop such a system at a low cost that can be a viable solution to various industrial sectors.

\section{References}

1. J.-P. Kruth, G. Levy, R. Schindel, T. Craeghs, E. Yasa, Consolidation of polymer powders by selective laser sintering, in Proceedings of the 3rd International Conference on Polymers and Moulds Innovations (2008) 15-30

2. P.D. Hilton, P.F. Jacobs, Rapid tooling: technologies and industrial applications, New York, 2000

3. D. Gu, G. Zhang, Selective laser melting of novel nanocomposites parts with enhanced tribological performance: nanocrystalline $\mathrm{TiC} / \mathrm{Ti}$ nanocomposites parts were built via SLM technology and the densification, microstructures, microhardness and tribological performance were, Virtual Phys. Prototyp. 8 (2013) 11-18

4. I. Gibson, D. Shi, Material properties and fabrication parameters in selective laser sintering process, Rapid Prototyp. J. 3 (1997) 129-136

5. F. Calignano, D. Manfredi, E.P. Ambrosio, L. Iuliano, P. Fino, Influence of process parameters on surface roughness of aluminum parts produced by DMLS, Int. J. Adv. Manufactur. Technol. 67 (2013) 2743-2751

6. N. Hopkinson, P. Erasenthiran, High speed sintering-early research into a new rapid manufacturing process, In Solid Freeform Fabrication Symposium (2004) 312-320

7. B. Khoshnevis, B. Asiabanpour, M. Mojdeh, K. Palmer, SIS - a new SFF method based on powder sintering, Rapid Prototyp. J. 9 (2003) 30-36

8. H. Wu et al., Recent developments in polymers/polymer nano composites for additive manufacturing, Progr. Mater. Sci. (2020) 100638 
9. S. Berretta, O. Ghita, K.E. Evans, Morphology of polymeric powders in Laser Sintering (LS): from polyamide to new PEEK powders, Eur. Polym. J. 59 (2014) 218-229

10. K. Palmer, B. Khoshnevis, Performance factors in the selective inhibition of sintering process, in IIE Annual Conference. Proceedings. Institute of Industrial and Systems Engineers (IISE) (2003) 1.

11. D. Rajamani, B. Esakki, Examining mechanical strength characteristics of selective inhibition sintered HDPE specimens using RSM and desirability approach, in IOP Conference Series: Materials Science and Engineering 234 (2017) 12002

12. B. Esakki, D. Rajamani, P. Arunkumar, An intelligent modeling system to predict mechanical strength characteristics of selective inhibition sintered parts using fuzzy logic approach, Mater. Today: Proc. 5 (2018) 11727-11737

13. S.M. Baligidad, U. Chandrasekhar, K. Elangovan, S. Shankar, Investigation of parameters influencing mechanical properties in SIS by using RSM, Int. J. Mater. Product Technol. 58 (2019) 178-200

14. C.R. Gagg, P.R. Lewis, In-service fatigue failure of engineered products and structures - case study review, Eng. Fail. Anal. 16 (2009) 1775-1793

15. A. Bhaduri, Mechanical Properties and Working of Metals and Alloys (Springer, Singapore, 2018)

16. J. Happian-Smith, An introduction to modern vehicle design (Elsevier, 2001)

17. M. Schmid, K. Wegener, Additive manufacturing: polymers applicable for laser sintering (LS), Proc. Eng. 149 (2016) $457-464$

18. R.D. Goodridge, C.J. Tuck, R.J.M. Hague, Laser sintering of polyamides and other polymers, Progr. Mater. Sci. 57 (2012) 229-267

19. S. Dadbakhsh, L. Verbelen, O. Verkinderen, D. Strobbe, P. Van Puyvelde, J.-P. Kruth, Effect of PA12 powder reuse on coalescence behaviour and microstructure of SLS parts, Eur. Polym. J. 92 (2017) 250-262

20. D. Rouholamin, N. Hopkinson, An investigation on the suitability of micro-computed tomography as a non-destructive technique to assess the morphology of laser sintered nylon 12 parts, Proc Inst. Mech. Eng. B 228 (2014) $1529-1542$

21. M. Schmidt, D. Pohle, T. Rechtenwald, Selective laser sintering of PEEK, CIRP Ann. 56 (2007) 205-208

22. M. Pavan, T. Craeghs, P. Van Puyvelde, J. Kruth, W. Dewulf, Understanding the link between process parameters, microstructure and mechanical properties of laser sintered PA12 parts through X-ray computed tomography, 2016.

23. W. Zhu et al., A novel method based on selective laser sintering for preparing high-performance carbon fibers/ polyamide12/epoxy ternary composites, Sci. Reports 6 (2016) 33780

24. M. Vasquez, B. Haworth, N. Hopkinson, Optimum sintering region for laser sintered nylon-12, Proc. Inst. Mech. Eng. B 225 (2011) 2240-2248

25. L. Verbelen, S. Dadbakhsh, M. Van den Eynde, J.-P. Kruth, B. Goderis, P. Van Puyvelde, Characterization of polyamide powders for determination of laser sintering processability, Eur. Polym. J. (2016) 163-174
26. B. Van Hooreweder, F. De Coninck, D. Moens, R. Boonen, P. Sas, Microstructural characterization of SLS-PA12 specimens under dynamic tension/compression excitation, Polym. Testing 29 (2010) 319-326

27. B. Van Hooreweder, D. Moens, R. Boonen, J.-P. Kruth, P. Sas, On the difference in material structure and fatigue properties of nylon specimens produced by injection molding and selective laser sintering, Polym. Testing 32 (2013) 972-981

28. B. Van Hooreweder, J.-P. Kruth, High cycle fatigue properties of selective laser sintered parts in polyamide 12 , CIRP Ann. 63 (2014) 241-244

29. J. Munguia, K. Dalgarno, Fatigue behaviour of laser sintered Nylon 12 in rotating and reversed bending tests, Mater. Sci. Technol. 31 (2015) 904-911

30. U.S.P.C. Vi and U.S.P.C. Vi, DuraForm ${ }^{\circledR}$ PA Plastic DuraForm ${ }^{\circledR}$ PA Plastic.

31. Dtm, S.L.S. process and DTM's DuraForm PA, Material Data Sheet.

32. B. Esakkia, D. Rajamania, P. Arunkumara, An intelligent modeling system to predict mechanical strength characteristics of selective inhibition sintered parts using fuzzy logic approach, Mater. Today 5 (2018) $11727-11737$

33. ASTM D7771-Standard Test Method for Uniaxial Fatigue Properties of Plastics, ASTM International, 2012

34. F.K.M. Guideline, Analytical strength assessment of components in mechanical engineering, vol. 5, Norma, Frankfurt/Main: Forschungskuratorium Maschinenbau (FKM), 2003

35. P. Wright, X. Fu, I. Sinclair, S.M. Spearing, Ultra high resolution computed tomography of damage in notched carbon fiber - epoxy composites, J. Compos. Mater. 42 (2008) 1993-2002

36. D. Bas, I.H. Boyac1, Modeling and optimization I: Usability of response surface methodology, J. Food Eng. 78 (2007) $836-845$

37. D.B. McDonald, W.J. Grantham, W.L. Tabor, M.J. Murphy, Global and local optimization using radial basis function response surface models, Appl. Math. Model. 31 (2007) 2095-2110

38. G.E.P. Box, D.W. Behnken, Some new three level designs for the study of quantitative variables, Technometrics 2 (1960) $455-475$

39. H. Öktem, T. Erzurumlu, H. Kurtaran, Application of response surface methodology in the optimization of cutting conditions for surface roughness, J. Mater. Proc. Technol. 170 (2005) 11-16

40. R.H. Myers, D.C. Montgomery, C.M. Anderson-Cook, Response surface methodology: process and product optimization using designed experiments, John Wiley \& Sons (2016)

41. M.M.D. Zulkali, A.L. Ahmad, N.H. Norulakmal, Oryza sativa L. husk as heavy metal adsorbent: optimization with lead as model solution, Bioresource Technol. 97 (2006) 21-25

42. D. Pokhrel, T. Viraraghavan, Arsenic removal from aqueous solution by iron oxide-coated fungal biomass: a factorial design analysis, Water, Air, Soil Pollution 173 (2006) 195 
43. J. Antony, Design of experiments for engineers and scientists, Elsevier (2014)

44. S.F.S. Shirazi et al., A review on powder-based additive manufacturing for tissue engineering: selective laser sintering and inkjet 3D printing, Sci. Technol. Adv. Mater. 16 (2015) 033502

45. T.D. Fender, Thermal spray high performance polymer coatings, Mater. Technol. 11 (1996) 16-20

Cite this article as: Mesfin Sisay, Esakki Balasubramanian, Optimization of fatigue strength of selective inhibition sintered polyamide 12 parts using RSM, Manufacturing Rev. 7, 23 (2020) 